\title{
Exposure to hydrogen fluoride: an experimental study in humans of concentrations of fluoride in plasma, symptoms, and lung function
}

\author{
Kristin Lund, Jan Ekstrand, Jacob Boe, Per Søstrand, Johny Kongerud
}

\begin{abstract}
Objectives-To study the absorption of inhaled hydrogen fluoride (HF) by measuring plasma fluorides and HF concentrations in the breathing zone during exposure to HF. A possible dose-effect relation was investigated by following airway symptoms and lung function-that is, forced expiratory volume in one second $\left(F_{1}\right)$ and forced vital capacity (FVC)during and after exposure to HF.
\end{abstract}

Methods-20 healthy, male volunteers were exposed for one hour to constant HF concentrations that ranged from 0.2 to $5.2 \mathrm{mg} / \mathrm{m}^{3}$; these concentrations are known to occur among potroom workers in the primary aluminium industry. Plasma fluorides were analysed before, during, and after exposure. Symptoms from the eyes and the upper and lower airways were registered and graded from 1 to 5 with a standardised questionnaire.

Results-The total symptom score was significantly increased at the end of exposure for all the subjects as a group $(P<0.01)$ and for the group exposed to HF below the present Norwegian standard for total fluorides $0.6 \mathrm{mg} / \mathrm{m}^{3}(P=0.05)$. No change was detected in $\mathrm{FEV}_{1}$, although a significant decrease was found in FVC in the group exposed to fluorides below the hygienic standard $(n=9)$ and for the entire group $(n=23)$. Almost all the symptoms had disappeared four hours after the end of exposure. Symptom scores from the upper airways were significantly correlated with the HF concentration $(r=0.62, P=0.002)$, the change in plasma fluoride concentration $(\Delta \mathbf{C})$ $(r=0.51, P=0.01)$, and the maximum plasma fluoride concentration $\left(C_{\max }\right)(r=$ $0.42, P=0.05)$. A significant correlation was also found between the total symptom score for airways and the HF concentration.

Conclusions-The present study showed a strong relation between inhaled HF and concentrations of fluoride in plasma. Upper airway and eye symptoms occurred after one hour of exposure to HF even when below the Norwegian hygienic standard for fluorides.

(Occup Environ Med 1997;54:32-37)

Keywords: fluorides; airway symptoms; lung function
Fluorides are used in a variety of industriesfor example, in the production of aluminium, steel, phosphate fertilisers, phosphoric acid, glass, ceramic, and brick products. Fluorides may therefore appear as pollutants emitted into the air in the working environment and outside the workplace. Although new technology and improved occupational hygiene programmes have reduced air emissions, fluorides are still one of the main environmental problems in the primary aluminium industry. Epidemiological studies of aluminium potroom workers have shown an association between exposure to fluoride and the occurrence of asthmatic symptoms. ${ }^{1}$ Pollutants from the aluminium industry may also influence the respiratory health of the general population. Recently, Søyseth and coworkers found a significant association between air pollution and bronchial hyperresponsiveness in children living in the vicinity of an aluminium plant. ${ }^{2}$

Hydrogen fluoride (HF) is one of the main gaseous fluoride components in the working environment in the primary aluminium industry. It has been shown to cause inflammatory responses in the lower airways of healthy volunteers after one hour of exposure in concentrations that usually occur in the aluminium industry $\left(<5 \mathrm{mg} / \mathrm{m}^{3}\right) \cdot{ }^{3}$ Machle and coworkers have described exposure to $26 \mathrm{mg} / \mathrm{m}^{3}$ for three minutes that induced lower airway irritation and mild symptoms from the eyes and nose. ${ }^{4}$ After accidental exposure in which the actual exposure concentrations were unknown, features such as chills, fever, chest tightness, cyanosis, pulmonary oedema, and pulmonary haemorrhagic oedema are described. ${ }^{56}$ On the basis of animal studies, Machle and Kitzmiller ${ }^{7}$ found concentrations of up to $15 \cdot 2 \mathrm{mg} / \mathrm{m}^{3}$ to be tolerable, but human exposure to lower concentrations of $\mathrm{HF}$ $\left(<1.6 \mathrm{mg} / \mathrm{m}^{3}\right)$ has been reported to cause symptoms of the upper airways. ${ }^{89}$

Ehrnebo and Ekstrand $\mathrm{d}^{10}$ followed the exposure to fluoride and the corresponding plasma concentrations in 41 workers in an aluminium plant during a period of eight hours. They found a significant correlation between the amount of gaseous fluoride and both the area below the plasma fluoride time curve and the amount of fluoride excreted. However, quantitative information on the relative absorption from inhaled HF is lacking - such as defined concentrations of HF in the inhalation zone and the resulting concentrations of fluoride in plasma in humans as well as threshold values for airway symptoms. 
The objective of the present study was therefore to study the absorption of inhaled $\mathrm{HF}$ by means of concentrations of fluoride in plasma and $\mathrm{HF}$ in the breathing zone during exposure. Also, the effect of exposure to HF on airway symptoms and spirometry, as well as a possible dose-response relation, was investigated.

\section{Material and methods \\ SUBJECTS}

Twenty healthy, non-smoking male volunteers, aged 21-44 years, participated in the study. They all gave written informed consent and the study was approved by the local ethics committee. All the subjects underwent a physical examination including a chest radiograph. Subjects with any history of airway infection during the six weeks before the start of the study or during the study period, or with a history of asthma were excluded. Two subjects had hay fever and one of them showed an increased total IgE value of $210 \mathrm{kU} / 1$ (upper normal value $122 \mathrm{kU} / \mathrm{l}$ ). Another subject also had an increased total IgE $(220 \mathrm{kU} / \mathrm{l})$ without having a history of allergy. The rest were not atopic or allergic. No one had any history of serious respiratory illness or had been previously exposed occupationally to fluorides. All the subjects had a normal ECG on bicycle ergometry (75 W for 15 minutes). Haemoglobin, sedimentation rate, leucocytes, platelets, eosinophils, electrolytes, and liver function tests were within the reference range.

\section{CHEMICAL AND PHYSICAL PROPERTIES OF HYDROGEN FLUORIDE}

Hydrogen fluoride is a colourless gas with a pungent smell. It is highly water soluble and, although weakly dissociated in water, is a strong proton donor in the class of superacids. It was prepared by the dynamic dilution of $\mathrm{HF}$ from pressurised gas cylinders $\left(40 \mathrm{dm}^{3}, 150\right.$ atm, $318-4016 \mathrm{mg} / \mathrm{m}^{3}$ ). The cylinders were certified according to calibration standards. The producer (Messer Griesheim, Germany) states the accuracy of analysis to be better than $3 \%$. The exposure to HF took place in a specially designed chamber.

\section{INHALATION CHAMBER}

The chamber had a volume of $19.2 \mathrm{~m}^{3}$ $(2.50 \mathrm{~m} \times 2.77 \mathrm{~m} \times 2.77 \mathrm{~m})$ with an air lock and an observation window. The chamber was constructed of extruded aluminium alloy profiles, AA 6082 quality $(98 \% \mathrm{Al}, 0.5 \% \mathrm{Mg}, 1 \%$ $\mathrm{Si}$ ) for the load bearing constructions and AA $5052(97 \% \mathrm{Al}, 2 \cdot 5 \% \mathrm{Mg})$ for the plates. The ceiling and floor were made of perforated plates which could be removed and the chamber was equipped with a water tap and a drain for cleaning purposes. The pressure inside the chamber was kept lower than outside it to avoid polluting the laboratory area.

\section{ADMINISTRATION OF HYDROGEN FLUORIDE}

The HF was passed directly from gas cylinders into the ventilation duct feeding the chamber through specially made orifices. The gas was regulated with orifices of different sizes and by the pressure of the gas (10 atm). The gas was fed into the ventilation duct countercurrent to the airflow to induce turbulence and promote the mixing of the concentrated gas into the air. Low gas flow (from $0 \cdot 1 \mathrm{dm}^{3} / \mathrm{min}$ ) and high pressure (2-10 atm) demanded orifices with diameters as small as $50 \mu \mathrm{m}$ which were carefully drilled under observation with a microscope. All gas tubes, regulators, tubes, and orifices were of ANSI 316 quality $(17 \% \mathrm{Cr}$, $12 \% \mathrm{Ni}$ ). The gas flow was measured by a mass flowmeter (top-trak 821-SS, Sierra Instruments, USA).

The subjects were divided into three different groups according to their exposure to HF; $<0.6 \mathrm{mg} / \mathrm{m}^{3}$ (current Norwegian hygienic standard value for total fluorides), $0.7-2.4 \mathrm{mg} / \mathrm{m}^{3}$ (intermediate level), and $>2.5$ (former Norwegian hygienic standard value, until 1990)-5.2 $\mathrm{mg} / \mathrm{m}^{3}$ (table 1 ). These exposure concentrations have been shown to occur in workplaces at aluminium smelters. ${ }^{11}$

\section{SAMPLING AND ANALYSIS OF HYDROGEN \\ FLUORIDE}

Fluoride exposure was precalculated approximately. The exact exposures used in the analyses were determined by analyses of fluorides absorbed on cellulose pads impregnated with sodium formate. The filters were kept in a standard aerosol sampling cassette with AFC 123 personal sampling pumps (Casella London, England) at a flow rate of two $\mathrm{dm}^{3} / \mathrm{min}$ and air was collected from the breathing zone during the exposure. The HF was desorbed from the filters and analysed with a fluoride selective electrode. ${ }^{12}$ The exposure to HF was kept constant as continuously measured by a Sensidyne XP-R electrochemical sensor (Sensidyne, USA).

\section{INHALATION PROCEDURE}

After equilibration of the gas concentration in the chamber, the subjects entered the chamber and were exposed for 60 minutes. For the first 45 minutes, the subjects rested and they then had a 15 minute fixed working load of $75 \mathrm{~W}$ on a bicycle ergometer. Each subject was exposed to a constant concentration of $\mathrm{HF}$ within the range $0 \cdot 2-5 \cdot 2 \mathrm{mg} / \mathrm{m}^{3}$. The subjects were exposed once, apart from three, who were exposed twice, three months apart. As $\mathrm{HF}$ is absorbed by clothes and hair, the subjects were dressed in overalls and helmets to minimise any systematic bias that could be introduced by differences in absorption.

\section{SYMPTOMS}

Symptoms were recorded before the start of exposure, after 30 and 60 minutes of exposure, and finally four and 24 hours after the end of exposure. The results were registered on a standardised questionnaire where symptoms from the eyes and the upper and lower airways were graded on a scale of 0 to 5; 0 representing no symptoms, 1 very mild symptoms, and 5 the most severe symptoms. The symptoms from the upper airways, (the nose and throat), and the eyes were itching and 
Figure 1 Concentrations of fluoride in plasma before, during, and after 60 minutes of exposure to $\mathrm{HF}$ at doses of $0 \cdot 7-2 \cdot 4 \mathrm{mg} / \mathrm{m}^{3}(n=7)$. of fluoride in plasma before, during, and after $H F$ at doses of $2 \cdot 5-5 \cdot 2 \mathrm{mg} / \mathrm{m}^{3}(n=7)$.
Figure 2 Concentrations 60 minutes of exposure to
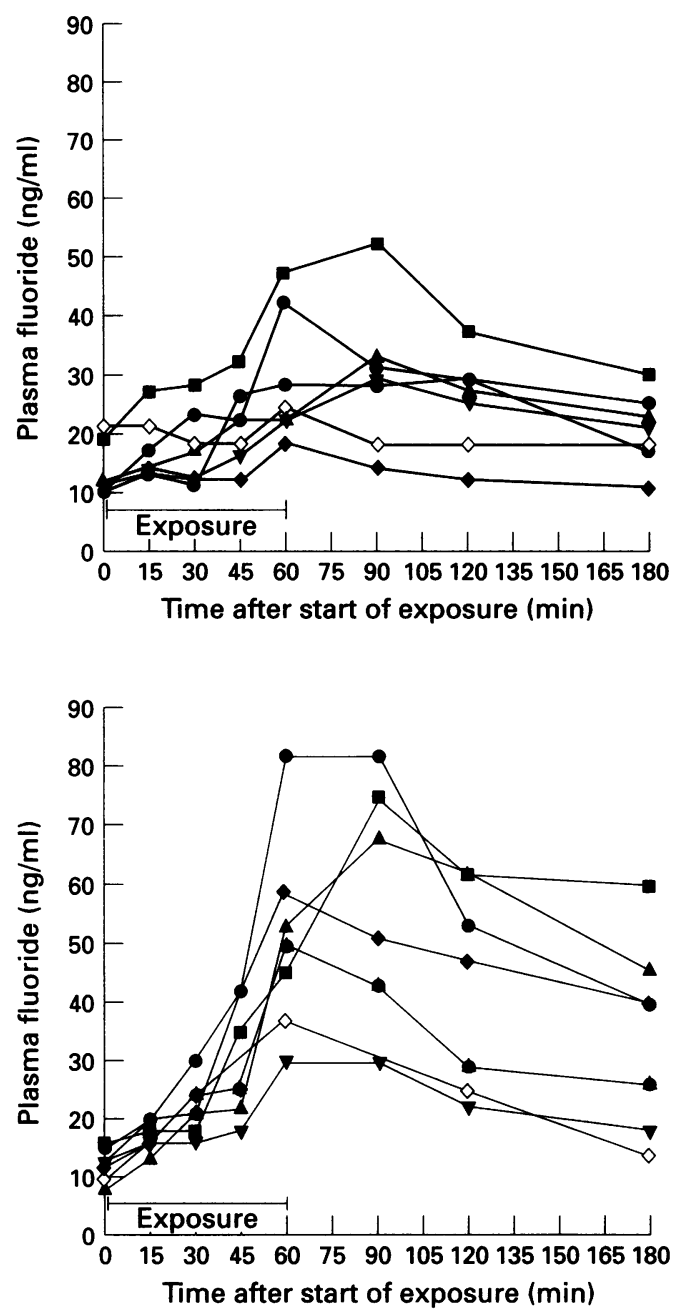

soreness. From the lower airways the subjects were asked to report chest tightness and soreness, coughing, expectoration, and wheezing. We were unable to perform the exposure blind because the subjects recognised the pungent smell of HF.

\section{LUNG FUNCTION}

Lung function was measured by spirometry $\left(\mathrm{FEV}_{1}\right.$ and $\mathrm{FVC}$ ) according to the guidelines suggested by the European Respiratory Society ${ }^{13}$ apart from the fact that the test was conducted with the subject in an upright standing position. In all subjects baseline $\mathrm{FEV}_{1}$ and FVC were above $80 \%$ of predicted. ${ }^{13}$ A portable spirometer (Microspirometer) was used immediately before entering the test chamber, every 15 minutes during exposure, immediately after exposure,

Table 1 Age, plasma creatinine, concentration of fluoride in plasma before exposure $\left(C_{0}\right)$, and the maximum value $\left(C_{\max }\right)$ after exposure to $H F$ at different doses

\begin{tabular}{|c|c|c|c|}
\hline & \multicolumn{3}{|c|}{ Concentration of $H F\left(\mathrm{mg} / \mathrm{m}^{3}\right)$} \\
\hline & $\begin{array}{l}0 \cdot 2-0 \cdot 6 \\
(n=9)\end{array}$ & $\begin{array}{l}0 \cdot 7-2 \cdot 4 \\
(n=7)\end{array}$ & $\begin{array}{l}2 \cdot 5-5 \cdot 2 \\
(n=7)\end{array}$ \\
\hline Age (y, mean (range)) & $31(22-44)$ & $23(21-44)$ & $31(22-45)$ \\
\hline $\begin{array}{l}\text { (interquartile range) }) \\
\mathrm{C}_{0}(\mathrm{ng} / \mathrm{ml} \text {, median }\end{array}$ & $100(91-102)$ & $100(85-106)$ & $98(94-102)$ \\
\hline (interquartile range)) & $22 \cdot 0(15 \cdot 5-28 \cdot 5)$ & $12 \cdot 0(12 \cdot 0-19 \cdot 0)$ & $12 \cdot 0(9 \cdot 0-13 \cdot 0)$ \\
\hline $\begin{array}{l}\mathrm{C}_{\max }(\mathrm{ng} / \mathrm{ml} \text {, median } \\
\text { (interquartile range)) }\end{array}$ & $22 \cdot 0(19 \cdot 5-29 \cdot 0)$ & $29 \cdot 0^{\star}(24 \cdot 0-42 \cdot 0)$ & $59 \cdot 0^{\star}(37 \cdot 0-75 \cdot 0)$ \\
\hline
\end{tabular}

$\star \mathrm{P}<0.05, \mathrm{C}_{\max }-\mathrm{C}_{0}$ with Wilcoxon's rank sum test for paired observations.
30 minutes after exposure, and every hour thereafter until four hours after exposure.

\section{FLUORIDE ANALYSIS}

Samples were collected by a nurse from the antecubital vein on entering the chamber and then $15,30,45,60,90,120$, and 180 minutes after the start of exposure. The subjects went outside the chamber for each blood sample, and the time spent outside was added to exposure time (three minutes on average for the sampling during exposure). After centrifugation, the plasma was separated, frozen immediately, and stored at $-70^{\circ} \mathrm{C}$ until it was analysed for fluoride by a fluoride ion sensitive electrode. ${ }^{14}$

\section{STATISTICS}

Comparisons between symptom scores and lung function data before and after exposure were made with Wilcoxon's non-parametric test for paired samples and Spearman's coefficient was applied to detect correlations between categoric variables. Kruscal-Wallis one way analysis of variance by ranks was used to examine differences in symptom scores and lung function between groups classified by different exposures. Linear regression analyses were performed to examine the association between plasma fluorides and exposure to HF.

The Kruscal-Wallis one way analysis of variance by ranks was used to compare the three HF groups by baseline concentrations of fluoride in plasma. Analyses were performed with SPSS for Windows, version $6 \cdot 0$.

\section{Results}

CONCENTRATIONS OF FLUORIDE IN PLASMA

Figures 1 and 2 show the increase in concentration of fluoride in plasma in seven subjects exposed to $0 \cdot 7-2.4 \mathrm{mg} / \mathrm{m}^{3} \mathrm{HF}$ and seven subjects exposed to $2 \cdot 5-5 \cdot 2 \mathrm{mg} / \mathrm{m}^{3} \mathrm{HF}$ for one hour. In the group with the exposure range of $0.2-0.6 \mathrm{mg} / \mathrm{m}^{3} \mathrm{HF}(\mathrm{n}=9)$, no increase in plasma fluoride could be detected, but baseline concentrations of fluoride in plasma $\left(\mathrm{C}_{0}\right)$ were significantly higher in this group than in the other two groups. A significant increase in concentration of fluoride in plasma $\left(\mathrm{C}_{\max }\right)$ occurred in the groups exposed to 0.7-2.4 and $2 \cdot 5-5 \cdot 2 \mathrm{mg} / \mathrm{m}^{3} \mathrm{HF}$ (table 1). At exposures between 0.7 and $2.4 \mathrm{mg} / \mathrm{m}^{3}, \mathrm{C}_{\max }$ was registered 60 minutes after the start of exposure in three subjects, 90 minutes in three subjects, and 120 minutes in one subject (fig 1). Among the subjects who were exposed to over $2.5 \mathrm{mg} / \mathrm{m}^{3}$, five had $\mathrm{C}_{\max } 60$ minutes and two 90 minutes after the start of exposure (fig 2). The plasma concentration then declined but was still high 180 minutes after the start of exposure compared with baseline in all subjects but one (figs 1 and 2). Figure 3 shows the correlation between the concentration of $\mathrm{HF}$ in the inhaled air and the increase in fluoride in plasma $(r=0.95, \mathrm{P}<0.001)$-that is, the difference between baseline and maximum concentration of fluoride in plasma $(\Delta \mathrm{C})$.

In a linear regression analysis no association between FVC or $\mathrm{FEV}_{1}$ and plasma fluoride 
Figure 3 Correlation between concentration of $H F$ in the breathing zone during exposure and the difference in concentrations of fluoride in plasma before exposure $\left(C_{\odot}\right)$ and the maximum value after exposure $\left(C_{\max }\right),(r=$ $0.95, P<0.001)$.

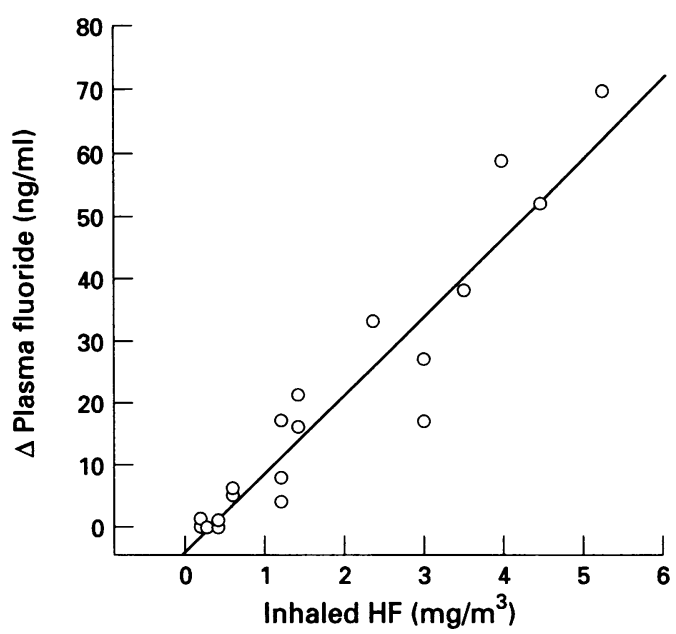

was found. Also no association was found between plasma fluoride at baseline $\left(C_{0}\right)$ and maximum plasma fluoride $\left(\mathrm{C}_{\max }\right)$ after exposure to $\mathrm{HF}$. We did find an increase in plasma fluoride $\left(\mathrm{C}_{\max }-\mathrm{C}_{0}\right)$ with increasing exposure concentrations (Kruscal-Wallis; $P<0.001$ ).

\section{CLINICAL SYMPTOMS}

Five subjects reported minor symptoms on the questionnaire before exposure, although they denied having such symptoms at the clinical examination and they had no clinical signs before entering the chamber. Three of the subjects reported very mild coughing or expectoration (score 1), and one subject reported coughing, expectoration, and itching of the nose and throat (total score 3 ). One subject reported coughing and itching from the nose and throat, both of which were given a score of 2 on the questionnaire, total score 4 .

The total symptom score was significantly increased after 60 minutes of exposure (table 2). For concentrations below the present

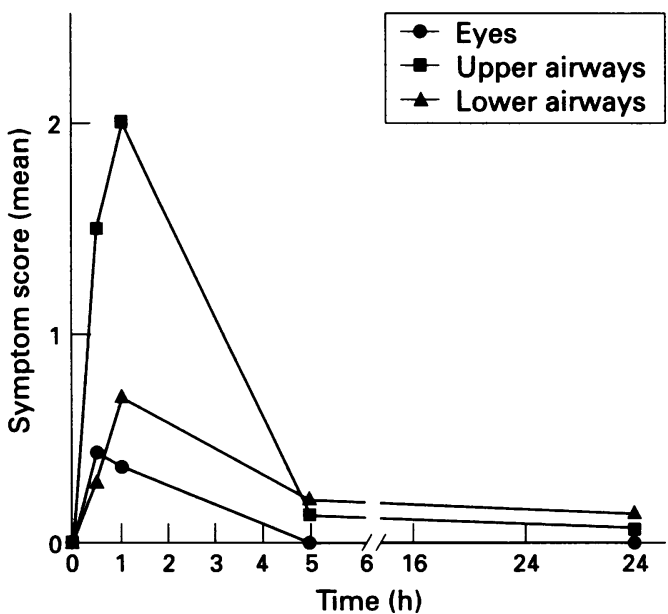

Figure 4 Symptoms related to exposure to $H F>0.6$ $\mathrm{mg} / \mathrm{m}^{3}(\mathrm{n}=14)$. Symptoms registered before, after $0 \cdot 5$, (at the end of exposure), 4, and 24 hours after the end of inhalation.

Norwegian hygienic standard for total fluorides $\left(0.6 \mathrm{mg} / \mathrm{m}^{3}\right)$, there was also a significant increase in the reporting of symptoms (total symptom score) at the end of exposure $(P<0.05)$. Symptoms from the upper airways were the most pronounced, and a significantly higher prevalence of total symptom scores and symptoms of the upper airways was found for exposure to HF over $2.5 \mathrm{mg} / \mathrm{m}^{3}$ compared with $0.2-0.6$ and $0.7-2.4 \mathrm{mg} / \mathrm{m}^{3} \quad(P<0.01$; Kruscal-Wallis). Symptoms from the upper airways dominated after exposure to $\mathrm{HF}$ in the highest dose range $(P<0.05)$ and the same trend was found among the subjects in the lowest dose group $(P=0.06)$. Lower airway symptoms were not reported to a significant degree in relation to exposure to $\mathrm{HF}$.

The FEV did not change during exposure, although a significant decrease in FVC was

Table 2 Symptom scores and lung function before and at the end of exposure for different doses of HF

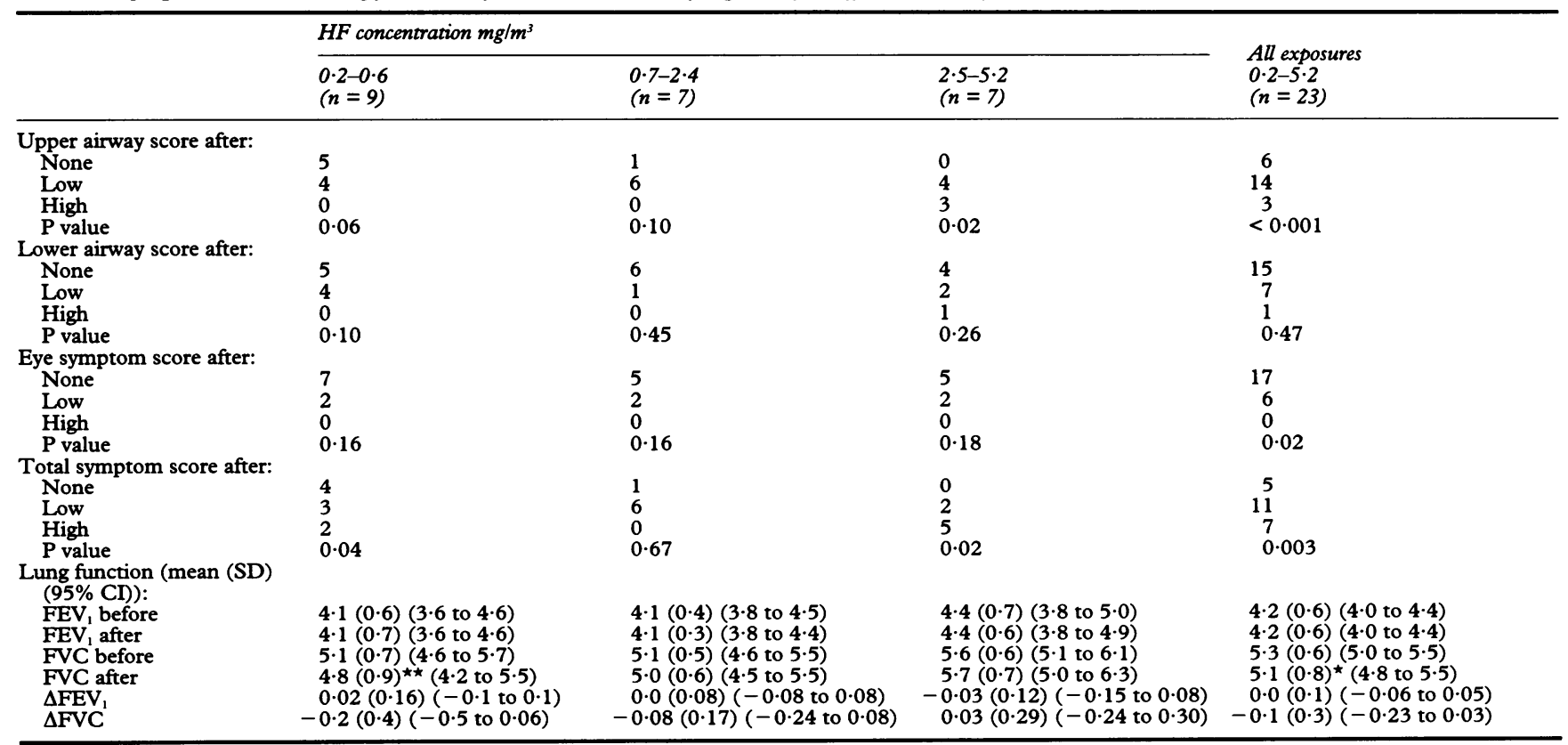


Table 3 Spearman rank correlation coefficients $(r)$ between symptom scores at the end of exposure and maximum concentration of fluoride in plasma $\left(C_{\max }\right)$, change in concentration of fluoride in plasma $(\Delta C)$, and the concentration of $H F$ in the air of the chamber during exposure (HF)

\begin{tabular}{|c|c|c|c|c|c|c|}
\hline \multirow[b]{2}{*}{ Score } & \multicolumn{2}{|l|}{$C_{\max }$} & \multicolumn{2}{|l|}{$\Delta C$} & \multicolumn{2}{|l|}{$H F$} \\
\hline & $r$ & Pvalue & $r$ & $P$ value & $r$ & $P$ value \\
\hline $\begin{array}{l}\text { Total symptom } \\
\text { Upper airway } \\
\text { Lower airway } \\
\text { Eye }\end{array}$ & $\begin{array}{l}0 \cdot 45 \\
0 \cdot 42 \\
0 \cdot 11 \\
0 \cdot 23\end{array}$ & $\begin{array}{l}0.03 \\
0.05 \\
0.61 \\
0 \cdot 30\end{array}$ & $\begin{array}{r}0.43 \\
0.51 \\
-0.01 \\
0.09\end{array}$ & $\begin{array}{l}0.04 \\
0.01 \\
0.96 \\
0.68\end{array}$ & $\begin{array}{l}0.53 \\
0.62 \\
0.08 \\
0.06\end{array}$ & $\begin{array}{l}0 \cdot 009 \\
0 \cdot 002 \\
0 \cdot 71 \\
0 \cdot 80\end{array}$ \\
\hline
\end{tabular}

found in the group exposed to less than $0.6 \mathrm{mg} / \mathrm{m}^{3} \mathrm{HF}(\mathrm{P}<0.01$, table 2$)$.

Figure 4 shows the mean symptom scores from the eyes and the upper and lower airways separately and the way they change in relation to exposure. The subjects mainly reported symptoms of the upper airways and a maximum score was recorded at the end of exposure. Almost all the symptoms had disappeared four hours after the end of exposure. One of the subjects reported chest tightness related to the exposure after half an hour, at the end of exposure, and four hours after the end of exposure ( $\max$ score $1 \cdot 5$ ).

There was a significant correlation between symptom scores of the upper airways and the concentration of $\mathrm{HF}$ as well as changes in plasma fluoride $(\Delta \mathrm{C})$ and maximum concentrations of plasma fluoride $\left(C_{\max }\right.$, table 3$)$. A significant correlation was also found between the total symptom score for airways and $\mathrm{HF}$ concentrations, $\Delta C$ and $C_{\max }$. Scores from the eyes and lower airway symptoms were not correlated with any of the exposure variables.

\section{Discussion}

The present study has shown a strong correlation between the concentration of HF in the inhaled air and concentrations of fluoride in plasma. Exposures above $2.5 \mathrm{mg} / \mathrm{m}^{3}$ were associated with pronounced symptoms from the upper respiratory tract.

Exposure to $\mathrm{HF}$ above $0.6 \mathrm{mg} / \mathrm{m}^{3}$ resulted in an increase in plasma fluoride. These results confirm similar findings in studies of rats. Morris and $\mathrm{Smith}^{15}$ reported a correlation between concentrations of airborne $\mathrm{HF}$ and plasma fluoride in the upper respiratory tract of exposed rats. They also found that more than $99.7 \%$ of the $\mathrm{HF}$ inhaled into the upper respiratory tract was rapidly removed from the air stream and absorbed into the systemic circulation. However, no information on the exact site of the fluoride absorption seems to exist. Both high reactivity and high solubility are needed for the fast and effective removal of a gas from the air stream in the upper respiratory tract; HF has both these properties as it is a weak acid ( $\mathrm{pKa}=3.45$ ) and is ionised at physiological $\mathrm{pH} .{ }^{16}$ This may explain the high degree of bioavailability and the rapid rise in the concentration of fluoride in plasma found in our study.

The subjects had different baseline concentrations of fluoride in plasma before the start of exposure $\left(C_{0}\right)$ and there may be several reasons for this. They met at 800 am and had no food restrictions. No guidelines were given on the use of fluorinated toothpaste, which strongly influences the individual baseline concentrations of fluoride in plasma. This may explain the high background concentrations recorded (table 1) and is probably one of the reasons why an increase in plasma fluorides was not found after exposure to $\mathrm{HF}$ at the lowest dose. Another explanation may just be a normal variation within the reference range.

Most of the symptoms which were reported came from the upper airways. This is in line with findings from both animal and human studies. ${ }^{4917}$ After the accidental release of HF from a petrochemical plant in Texas, subjects admitted to hospital presented with eye irritation $(41.5 \%)$, burning throat $(21 \%)$, headache $(20 \cdot 6 \%)$, and shortness of breath $(19 \cdot 4 \%){ }^{18}$ The individual exposure concentrations were not estimated, and a threshold for the appearance of symptoms was not indicated. The report did, however, suggest that symptoms of the upper airways were predominant after "diluted" exposure to HF.

This phenomenon of symptoms mainly from the eyes and upper airways is described for other highly water soluble gases as well. In human experimental studies of exposure to $\mathrm{SO}_{2}$, Sandstrøm and coworkers ${ }^{19}$ found a dose-dependent increase in nasal irritation and significantly more irritation of the throat during exposure at $5 \mathrm{mg} / \mathrm{m}^{3}$ than before it.

As the present study was not blind, the different symptoms may have been overreported. The dose-response relation is, however, not likely to be biased as the exposed subjects were not aware of the concentrations of $\mathrm{HF}$ and the dose-response trend indicated that the high symptom scores registered at fairly low concentrations of HF are not only caused by systematic overreporting.

The symptoms of the lower respiratory tract were mainly coughing and expectoration. As $\mathrm{HF}$ is a highly water soluble gas, it is remarkable that lower respiratory symptoms occurred at low exposures. As described in animal studies, the distribution and absorption of $\mathrm{HF}$ will probably depend on the inhalation route (the degree of nasal versus mouth breathing). ${ }^{15} 20$ This could imply that the absorption is different in humans, and a higher degree of mouth breathing because of physical activity (bicycle ergometry) will probably permit transport of HF further into the bronchial tree and might explain our findings. The regular use of airway protection even at low exposures is therefore recommended as previously suggested by Ehrnebo and Ekstrand. ${ }^{10}$

The reduction in FVC in the group that was exposed to the lowest dose of HF and for all the subjects as a group may show minor obstruction in the periphery of the lungs which could be theoretically explained by "air trapping" distally in the airways. Hjortsberg et al found the same mechanism after exposure to potassium aluminium tetrafluoride. ${ }^{17}$ However, the lack of significant change in FVC at higher concentrations of HF weakens the implication of this finding. No one in this study had obvious signs reflecting bronchial 
constriction.

In conclusion, the present study showed a strong dose dependent relation between concentrations of inhaled HF and plasma fluoride. Among the subjective symptoms that were registered during the 24 hours after one hour of exposure at low doses of HF, symptoms of the upper airways and eyes dominated and appeared even at concentrations similar to those occurring in the work atmosphere of primary aluminium production. According to our findings, the concentrations of HF should be kept well below $2.5 \mathrm{mg} / \mathrm{m}^{3}$ to avoid symptoms of the upper airways and eyes.

We are indebted to Mari-Anne Boe for performing the lung function tests and recording the symptoms and associate professor Sven Ove Samuelsen for statistical advice. The study was supported by the Working Environment Fund of the Confederation of Norwegian Business and Industry, the Nordic Aluminium Industry's Secretariat for Health Environment, and Safety (AMS), the Research Council of Norway, the Norwegian Asthma and Allergy Association, the Glaxo Research Fund, Norway, the Astra Research Fund, Norway, the Swedish Medical Research Council Project Numbers 11257-01A and 09439-05X, and the Swedish Patent Revenue Research Fund.

1 Kongerud J, Boe J, Søyseth V, Naalsund A, Magnus P. Aluminium potroom asthma: the Norwegian experience. Eur Respir F 1994;7:165-72.

2 Søyseth V, Kongerud J, Harr D, Strand O, Bolle R, Boe J. Relation of exposure to airway irritants in infancy to prevalence of bronchial hyper-responsiveness in schoolchildren. Lancet 1995;345:217-20.

3 Lund K, Refsnes M, Søstrand P, Schwarze P, Boe J, Kongerud J. Inflammatory cells increase in bronchoalveolar lavage fluid following hydrogen fluoride exposure. $A m$ f Respir Crit Care Med 1995;151:A259.

4 Machle W, Thamann F, Kitzmiller K, Cholak J. The inhalation of hydrogen fluoride. I The response following inhalation of hydrogen fluoride. I The response following 129-45.
5 Flood S. Hydrofluoric acid burns. Am Fam Physician 1988; 37:175-82.

6 Chela A, Reig R, Sanz P, Huguet E, Corbella J. Death due to hydrofluoric acid. Am F Forensic Med Pathol 1989;10: 47-8.

7 Machle W, Kitzmiller K. The effects of the inhalation of hydrogen fluoride. II Response following exposure to low hydrogen fluoride. II Response following
concentration. $\mathcal{F}$ Ind Hyg 1935;17:223-9.

8 Largent EJ. The metabolism of fluoride in man. Arch Ind Health 1960;21:318-23.

9 Alexeeff GV, Lewis DC, Ragle NL. Estimation of potential health effects from acute exposure to hydrogen fluoride using a "benchmark dose" approach. Risk Anal 1993; 13:63-9.

10 Ehrnebo M, Ekstrand J. Occupational fluoride exposure and plasma fluoride levels in man. Int Arch Occup Environ Health 1986;58:179-90.

11 Abramson MJ, Wlodarczyk JH, Saunders NA, Hensley MJ. Does aluminium smelting cause lung disease? $A m$ Rev Respir Dis 1989;139:1042-57.

12 Nagy K, Keul E. Evaluation of the FLAKT Sintalyzer, a new semiautomatic system for fluorine analysis within the aluminium industry. Presented at the Metallurgical Society, TMS paper selection. Metallurgical Society, 1978:A78-39.

13 Quanjer PH. Standardized lung function testing. Eur Respir f Suppl 1993;16:5-40.

14 Ekstrand J. A micromethod for the determination of fluoride in blood plasma and saliva. Calcified Tissue Research 1977;23:225-8.

15 Morris JB, Smith F. Regional deposition and absorption of inhaled hydrogen fluoride in the rat. Toxicol Appl Pharmacol 1982;62:81-9.

16 Smith F, Ekstrand J. The occurrence and chemistry of fluoride, chapter 1: Fluoride in dentistry. 2nd ed. Feierskov $\mathrm{O}$, ride, chapter 1: Fluoride in dentistry. 2nd ed. Feierskov O,

17 Hjortsberg U, Ørbæk P, Arborelius M Jr, Karlsson JE Upper airway irritation and small airways hyperreactivity due to exposure to potassium aluminium tetrafluoride fue to exposure to potassium aluminium tetrafluoride flux: an exter

18 Wing JS, Sanderson LM, Brender JD, Perrotta DM, Beauchamp RA. Acute health effects in a community after a release of hydrofluoric acid. Arch Environ Health 1991;46:155-60.

19 Sandstrøm T, Kolmodin-Hedman B, Stjernberg $N$ Andersson MC, Lofvenius G. Challenge test for sulfur dioxide-symptom and lung function measurements. Scand $₹$ Work Environ Health 1988;1:77-9.

20 Stavert DM, Archuleta DC, Behr MJ, Lehnert BE. Relative acute toxicities of hydrogen fluoride, hydrogen chloride and hydrogen bromide in nose- and pseudo-mouthbreathing rats. Fundam Appl Toxicol 1991;16:636-55.

\section{Correspondence and editorials}

Occupational and Environmental Medicine welcomes correspondence relating to any of the material appearing in the journal. Results from preliminary or small scale studies may also be published in the correspondence column if this seems appropriate. Letters should be not more than 500 words in length and contain a minimum of references. Tables and figures should be kept to an absolute minimum. Letters are accepted on the understanding that they may be subject to editorial revision and shortening.

The journal also publishes editorials which are normally specially commissioned. The Editor welcomes suggestions regarding suitable topics; those wishing to submit an editorial, however, should do so only after discussion with the Editor. 